\title{
Responses of Tolerant and Susceptible Kentucky Bluegrass Germplasm to Salt Stress
}

\author{
B. Shaun Bushman ${ }^{1}$ \\ USDA-ARS Forage and Range Research Unit, 695 N 1100 E, Logan, UT 84322-6300
}

Lijun Wang

Department of Plants, Soils, and Climate, Utah State University, 4820 Old Main Hill, Logan, UT

$84322-4820$

Xin Dai

Utah Agriculture Experiment Station, Utah State University, 4810 Old Main Hill, Logan, UT

$84322-4810$

Alpana Joshi and Joseph G. Robins
USDA-ARS Forage and Range Research Unit, 695 N 1100 E, Logan, UT 84322-6300

Paul G. Johnson

Department of Plants, Soils, and Climate, Utah State University, 4820 Old Main Hill, Logan, UT

$84322-4820$

AdDitional INDEX words. turfgrass, Poa pratensis, salt tolerance, electrolyte leakage, ATPase, thioredoxin h-type

\begin{abstract}
Much of semiarid western North America is salt affected, and using turfgrasses in salty areas can be challenging. Kentucky bluegrass (Poa pratensis L.) is relatively susceptible to salt stress, showing reduced growth, osmotic and ionic stress, and eventual death at moderate or high salt concentrations. Considerable variation exists for salt tolerance among kentucky bluegrass germplasm, but gaining consistency among studies and entries has been a challenge. In this study, two novel kentucky bluegrass accessions recently reported as salt tolerant (PI 371768 and PI 440603) and two cultivars commonly used as references (Baron and Midnight) were compared for their turf quality (TQ), stomatal conductance $\left(g_{\mathrm{S}}\right)$, leaf water potential ( $\left.\psi \mathrm{LEAF}\right)$, electrolyte leakage (EL), and accumulation of inorganic ions under salt stress. TQ, $\psi$ LEAF, and EL were highly correlated with each other while only moderately correlated with $g_{\mathrm{S}}$. The tolerant accessions showed higher $\psi$ LEAF and lower EL than the cultivars Midnight and Baron at increasing salt concentrations and over 28 days of treatment. The accumulation of sodium (Na) and calcium (Ca) in the leaves was highly correlated and did not vary significantly among the four entries. Genes involved in ion transport across membranes, and in antioxidant activities, were significantly induced on salt stress in the tolerant accessions relative to the susceptible. These data indicate the ability of tolerant accessions to ameliorate oxidative stress and prevent EL, and confirmed the tolerance of germplasm previously reported on while indicating mechanisms by which they tolerate the salt stress.
\end{abstract}

Much of semiarid western North America is salt affected (Szabolcs, 1989) due to alkaline water and insufficient leaching that would otherwise remove salts from weathering of minerals and groundwater (Pitman and Lauchli, 2002). Irrigation contributes to increased soil salinity in semiarid climates at times of high evapotranspiration coupled with inadequate leaching, lowquality irrigation water, or rising water tables that receive salts leached from the plant root zone (Carrow and Duncan, 1998). Other sources of landscape salinity include salts used for roadside deicing (Hutchinson, 1970) and recycled wastewater for landscape irrigation (Lockett et al., 2008; Marcum, 2006).

Kentucky bluegrass is a widely used cool-season species in cool, semiarid climates; however, it has relatively poor salt tolerance (Alshammary, 2013; Marcum, 2008). Many studies have attempted to assess the potential for salt tolerance among kentucky bluegrass cultivars through many varying methods

Received for publication 25 Mar. 2016. Accepted for publication 7 June 2016. We would like to acknowledge funding from the U.S. Golf Association, and the assistance of Lisa Michaels, Thomas Sprouse, Kathleen Coombs, and Tanya Oldham in data collection.

${ }^{1}$ Corresponding author. E-mail: shaun.bushman@ars.usda.gov.
(Alshammary et al., 2004; Horst and Taylor, 1983; Koch and Bonos, 2010; Koch et al., 2011; Liu et al., 2011; Poss et al., 2010; Qian et al., 2001; Robins et al., 2009; Rose-Fricker and Wipff, 2001; Suplick-Ploense et al., 2002; Torello and Rice, 1986). Most studies found that TQ, a measure of turf color, density, and texture, showed significant variation among cultivars under salt stress. Although various mechanisms have been suggested for the variation in salt tolerance, it was found that kentucky bluegrass did not have the ability to exclude salt outside of the leaves, nor was it effective in excluding ions in the root zones (Alshammary, 2013; Alshammary et al., 2004; $\mathrm{Xu}$ and Fujiyama, 2013). Compartmentalization or sequestration of $\mathrm{Na}$ ions into the vacuole or apoplast was presented as a potential mechanism by which the species could tolerate higher levels of salt (Alshammary, 2013; Marcum, 2008). This sequestration is hypothesized to be accompanied by antioxidant mechanisms to prevent cell damage (Hasegawa et al., 2000; Munns, 2005; Puyang et al., 2015), and physiological mechanisms to maintain turgor and water potential. Consistent with these findings, Bushman et al. (2016) identified genes involved in cellular ion and water transport [tonoplast intrinsic protein 
(TIP4-1), V-type ATPase subunit b, and H-type ATPase] and genes involved in maintenance of cellular redox state [thioredoxin h-type, glyceraldehyde 3-phosphate dehydrogenase (GAPDH), and glutathione S-transferase (GST)] in a transcriptome survey between a salt-tolerant and susceptible kentucky bluegrass accession.

Although substantial variation has been detected in assessments of kentucky bluegrass salt tolerance, cultivars often show changes of rank in relative salt tolerance, depending on the study methods. The cultivars Midnight and Baron, ubiquitous kentucky bluegrass cultivars often included in studies as checks, have shown a range of responses to salt stress (Koch and Bonos, 2010; Koch et al., 2011; Puyang et al., 2015); such that their relative salt tolerance is unclear. Robins et al. (2009) used a different approach to find kentucky bluegrass entries with putative salt tolerance. Although previous quantitative measures were intensive, which thereby limited the entry numbers, Robins et al. (2009) submersed multiple plants from many cultivars in increasingly concentrated saline solutions over time and measured the concentration of salts and number of days treated when a lethal dose, whereupon $50 \%$ of the plants were dead $\left(\mathrm{LD}_{50}\right)$, was reached for each entry. Rather than a mechanistic approach on relatively few entries, that method focused on turf color of multiple genotypes per entry and a higher number of entries. Although that method included the cultivar Midnight as a susceptible control, whether tolerant entries detected by Robins et al. (2009) would be tolerant under mechanistic approaches is unknown.

One of the purposes of this study was to confirm the salt tolerance of two putatively tolerant kentucky bluegrass accessions reported in Robins et al. (2009), and to investigate mechanisms by which those accessions respond to salt stress. The two accessions, PI 371768 and PI 440603, and the cultivars Baron and Midnight are measured in multiple greenhouse trials for TQ, $g_{\mathrm{S}}, \psi \mathrm{LEAF}, \mathrm{EL}$, and the accumulation of inorganic ions on control and salt treatments. In addition, the expression profiles of genes involved in cellular ion sequestration and antioxidant activities previously reported in Bushman et al. (2016) are characterized for variation between the tolerant accessions and susceptible cultivars. These results identify new germplasm sources of salt tolerance in kentucky bluegrass and pinpoint mechanisms by which those lines tolerate salt stress that may be useful for selection of other salt-tolerant kentucky bluegrass germplasm.

\section{Materials and Methods}

Plant materials, growth Conditions, and Stress TREATMENTS. Four kentucky bluegrass entries were used: collection PI 371768 from Alaska, collection PI 440603 from Kazakhstan, 'Midnight' (Meyer et al., 1984), and 'Baron' (Hurley and Ghijsen, 1980). The former two accessions were found to be salt tolerant through $\mathrm{LD}_{50}$ values at higher salt concentrations than other entries in Robins et al. (2009). Certified seed of the two cultivars was purchased from local seed retailers, whereas seed of the two collections was obtained from the National Plant Germplasm System in Pullman, WA. Seeds were germinated in Jan. 2013, and maintained in a research greenhouse at Utah State University (Logan, UT) under a 16-h photoperiod, temperatures of $25 / 15{ }^{\circ} \mathrm{C}$ (day/night), and photosynthetically active radiation from 350 to 500 $\mu \mathrm{mol} \cdot \mathrm{m}^{-2} \cdot \mathrm{s}^{-1}$. Plants were irrigated twice per week before and during the experiment with $21 \mathrm{~N}-2.2 \mathrm{P}-16.6 \mathrm{~K}$ water-soluble fertilizer (JR Peters, Allentown, PA), with a solution electrical conductivity (EC) of $1 \mathrm{dS} \cdot \mathrm{m}^{-1}$ and proportioned to deliver $100 \mathrm{mg} \cdot \mathrm{kg}^{-1} \mathrm{~N}$ with $1 \mathrm{~g}$ red iron oxide added to the concentrate yielding $6 \%$ iron delivered to the plant. For each irrigation event, sufficient irrigation was applied slowly to flush the soil and replace the solution within each pot. Two weeks before each experimental run, tillers of equal size of each entry were transplanted into $25.7-\mathrm{L}$ pots $(25.4-\mathrm{cm}$ diameter, $50.8-\mathrm{cm}$ depth) filled with a 3:1 sand: peatmoss media. Four plants were spaced equidistantly and randomized in each pot in a split-plot design with treatments as whole plots, with four replications, and entries as split plots. Thus, each experimental run included 16 pots. All pots were irrigated with the same fertilizer solution of $21 \mathrm{~N}-2.2 \mathrm{P}-16.6 \mathrm{~K}$ water-soluble fertilizer, but with $\mathrm{NaCl}$ (Thermo Fisher Scientific, Waltham, MA) added to fertilizer solutions of treated pots. The four salinity treatments imposed ECs of 1 (control), 6, 12, and $18 \mathrm{dS} \cdot \mathrm{m}^{-1}$, which corresponded to $0,16,24$, and $30 \mathrm{~mm}$ added $\mathrm{NaCl}$, respectively. Calcium chloride (Thermo Fisher Scientific) was also added at increasing concentrations necessary to maintain a $\mathrm{Na}$ absorption ratio of 3.5 (Lesch and Suarez, 2009), which mimics the type of salinity stress present in the alkaline soils of the semiarid western United States. Solution ECs were measured with a soil and water EC meter (FieldScout; Spectrum Technologies, Plainfield, IL). All plants were cut weekly to $10 \mathrm{~cm}$ from the soil level. Plant measurements continued for $28 \mathrm{~d}$ after the first salinity treatment. The entire experiment was conducted three times, with respective salt treatments beginning on 25 June 2013, 17 Sept. 2013, and 14 May 2014.

REPEATED MEASUREMENTS. To evaluate stress on the plants imposed by the salinity treatments, TQ, $g_{\mathrm{S}}, \psi \mathrm{LEAF}$, and EL were measured once each week on the treatments for 4 weeks. TQ was visually rated on a scale from 1 to 9 , where a rating of 1 represented completely necrotic (brown) plants and nine represented healthy plants with dark green, turgid leaf blades (Liu et al., 2011). భLEAF was measured using a portable pressure chamber (model 3005HGPL; Soilmoisture Equipment Corp., Santa Barbara, CA) and the protocols described in Liu et al. (2011) and Leksungnoen et al. (2014) were followed. The protocol used a fully developed shoot, which was cut slightly above the crown and placed in the pressure chamber with the cut end protruding from the chamber. Pressure was gradually increased in the chamber using compressed nitrogen until plant sap was observed at the cut end of the stem. At this point, $\psi L E A F$ is equal to the pressure in the chamber. $g_{S}$ measurements used a leaf porometer (model SC-1; Decagon Devices, Pullman, WA). Because leaves were narrower than the porometer chamber, four to five leaf blades were excised and quickly arranged side by side with the adaxial side of the leaves facing the porometer chamber. Measurements were conducted in less than $60 \mathrm{~s}$ to ensure the stomatal aperture was unchanged. EL was determined as described by Blum and Ebercon (1981), and reported as the percentage of the total electrolytes that leaked from cells during stress treatments.

Significance between entries, dates, and treatments were obtained using generalized linear mixed models implemented in SAS (version 9.4; SAS Institute, Cary, NC). As TQ, $g_{S}$, $\psi L E A F$, and EL were progressively measured in each experimental run, experimental runs and replications were considered random effects whereas treatment, entry, and date were fixed effects. Run interactions with entry and treatment were 
either not significant or Spearman rank correlation coefficients exceeded $r=0.60(P<0.01)$, such that data for each trait are presented as combined analyses of the three experimental runs. The EL trait analysis required a logit transformation to reach homoscedasticity and normality, such that means presented for that trait represent back-transformed data. All mean separations were based on least significant differences (LSD) at the 0.05 level. Pearson correlations were estimated among measures using the Corr procedure in SAS (version 9.4).

LEAF INORGANIC ION CONCENTRATIONS. On completion of the experimental runs one and two, aboveground plant material was collected from control and $6 \mathrm{dS} \cdot \mathrm{m}^{-1}$ treated plants (to ensure live plant material was sampled). Samples were freeze dried for analysis of cation concentrations using a dry-ashing method as per Miller (1998). About $200 \mathrm{mg}$ of dried, ground samples were heated to $550{ }^{\circ} \mathrm{C}$ for $4 \mathrm{~h}$ and extracted with $1 \mathrm{~N} \mathrm{HCL}$. Digested samples were analyzed for magnesium $(\mathrm{Mg})$, potassium $(\mathrm{K})$, $\mathrm{Ca}$, and $\mathrm{Na}$ using an atomic absorption spectrometer (PerkinElmer, Waltham, MA) at the U.S. Department of AgricultureAgricultural Research Service Great Basin Rangelands Research Unit, Reno, NV. For statistical analysis of elemental data, experimental run and replication were again considered random effects whereas entry and treatment were fixed effects. For leaf $\mathrm{Ca}$ and $\mathrm{Na}$ concentration, analyses required log transformations to reach homoscedasticity, such that the presented means represent back-transformed data. Mean separations were based on LSD at the 0.05 level for phenotypic measures. Pearson correlations were estimated among ion levels using the Corr procedure in SAS (version 9.4).

QUANTITATIVE REVERSE TRANSCRIPTION POLYMERASE CHAIN REACTION. On completion of the third experimental run, aboveground tissue from control and $6 \mathrm{dS} \cdot \mathrm{m}^{-1}$ treated plants (to ensure live plant material from susceptible samples was sampled) was harvested and frozen in liquid nitrogen. Total RNA was extracted from $\approx 200 \mathrm{mg}$ of ground samples using the Direct-Zol RNA extraction kit (Zymo Research Corp., Irvine, CA), quantified through spectrophotometry, and quality assured through denaturing gel electrophoresis. One microgram of total RNA was reverse transcribed using the Maxima First Strand cDNA Synthesis Kit (Thermo Fisher Scientific). Quantitative polymerase chain reaction used Fluidigm Dynamic Array integrated fluidic circuits for gene expression (96.96; Fluidigm, San Francisco, CA), Phusion DNA Polymerase, and EvaGreen DNA-binding dye (Biotium, Hayward, CA); following the advanced development protocol 1208-A1 from Fluidigm. Primers from the candidate genes were ordered from Eurofins MWG Operon (Louisville, KY), and were designed from sequences reported in Bushman et al. (2016), which are shown in Supplemental Table 1. Three technical replicates of each of four biological replicates were included, and $\beta$-tubulin was used as an internal control. Standard curves of both the target genes and $\beta$-tubulin were included in each replicate, and transcript expression values were quantified based on the standard curves and normalized relative to $\beta$-tubulin. Mean relative expression values are presented with SES of the means.

\section{Results}

Under control conditions, all four kentucky bluegrass entries had equivalent TQ ratings (Fig. 1). On salt treatments, the entries began to separate after $21 \mathrm{~d}$ of treatment, with PI 440603 and PI 371768 trending to the highest TQ measurements while 'Midnight' had the lowest TQ measurements. At $18 \mathrm{dS} \cdot \mathrm{m}^{-1}$ treatment, TQ from all entries dropped equivalently through 21 $\mathrm{d}$ of treatment. At $28 \mathrm{~d}$ of treatment, PI 440603 had the highest TQ, followed by PI 371768, with 'Baron' and 'Midnight' having the lowest TQ (Fig. 1).

$g_{\mathrm{S}}$ decreased as salt concentration increased, and as time from the treatment initiation increased (Fig. 2). However, $g_{S}$ also showed significant differences among the entries under control conditions as well as salt treatments. PI 440603 had the lowest $g_{\mathrm{S}}$ at $7 \mathrm{~d}$ of treatment and under the control treatment, but the highest $g_{\mathrm{S}}$ at $28 \mathrm{~d}$ of treatment under 12 and $18 \mathrm{dS} \cdot \mathrm{m}^{-1}$ salt treatments. Meanwhile, 'Baron' had the highest $g_{\mathrm{S}}$ under control conditions, yet was not significantly different from the lowest $g_{\mathrm{S}}$ values at salt treatments of 12 and $18 \mathrm{dS} \cdot \mathrm{m}^{-1}$. 'Midnight' and PI $371768 g_{\mathrm{S}}$ values fluctuated throughout the experiments, but were not significantly different from the lowest $g_{\mathrm{S}}$ values at higher salt treatments (Fig. 2).

$\psi L E A F$ also exhibited significant differences among the entries under control conditions as well as salt treatments (Fig. 3). However, on all three salt treatments, the $\psi \mathrm{LEAF}$ at $28 \mathrm{~d}$ of treatment exhibited a similar trend to TQ, with PI 440603 and PI 371768 trending or showing the highest $\psi$ LEAF, whereas 'Midnight' or 'Baron' had lower $\psi$ LEAF. By $18 \mathrm{dS} \cdot \mathrm{m}^{-1}$ salt and $28 \mathrm{~d}$ of treatment, PI 440603 had significantly higher $\psi$ LEAF than the other three entries (Fig. 3).

EL measurements were not significantly different under control conditions or at day 7 among any of the salt treatments, but separated significantly for the other dates and higher salt treatments (Fig. 4). At $6 \mathrm{dS} \cdot \mathrm{m}^{-1}$, PI 440603 had the lowest EL, followed by 'Baron', and then by PI 371768 and 'Midnight'. At $12 \mathrm{dS} \cdot \mathrm{m}^{-1}$, that same ranking persisted, with PI 440603 possessing substantially lower EL values than the other three
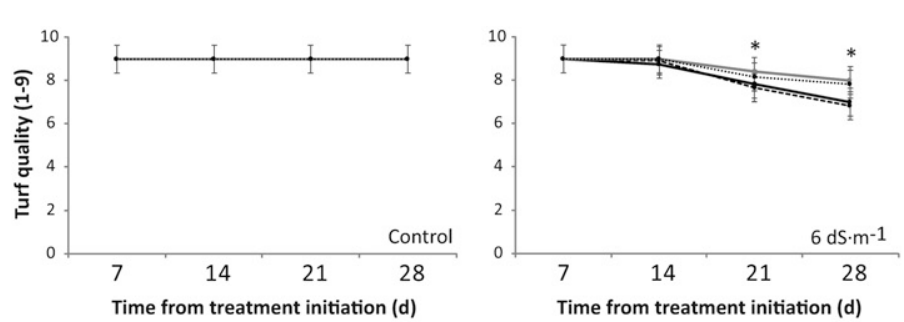

PI $440603 \quad$........... PI 371768
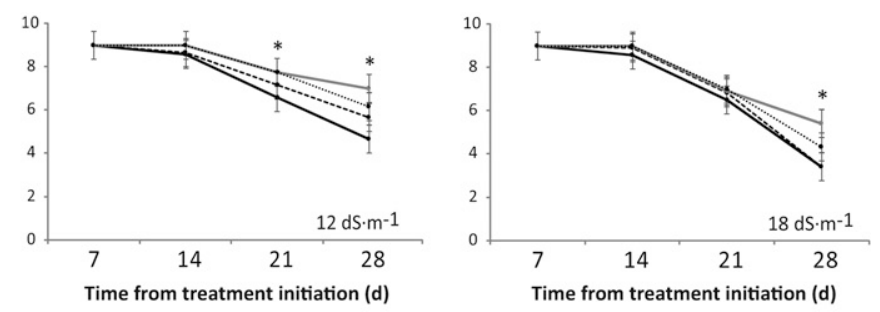

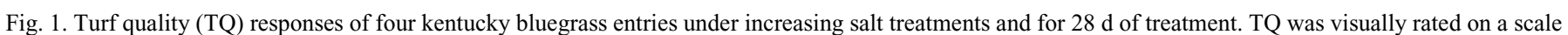
from 1 to 9 , where 1 represents necrotic plants and 9 represents healthy plants with dark green, turgid leaf blades. Error bars represent least significant difference values at $P<0.05$, and asterisks are shown adjacent to comparisons that were significantly different. 

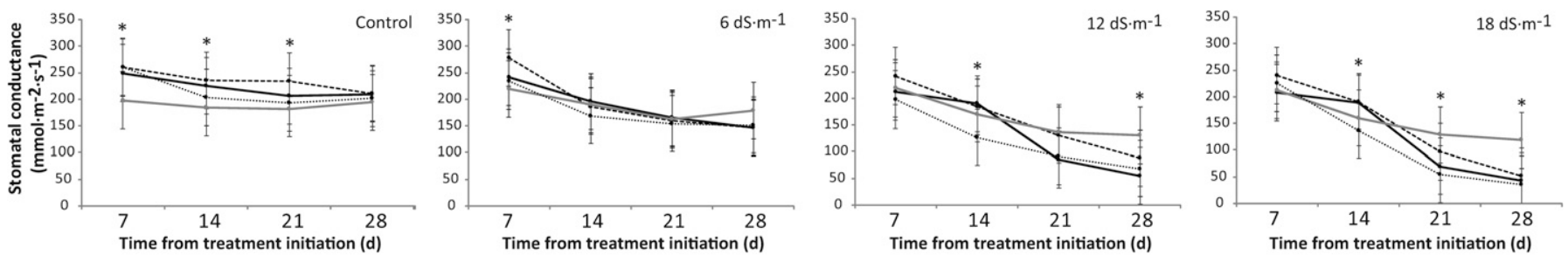

Fig. 2. $g_{\mathrm{S}}$ responses of four kentucky bluegrass entries under increasing salt treatments and for $28 \mathrm{~d}$ of treatment. Error bars represent least significant difference values at $P<0.05$, and asterisks are shown adjacent to comparisons that were significantly different.
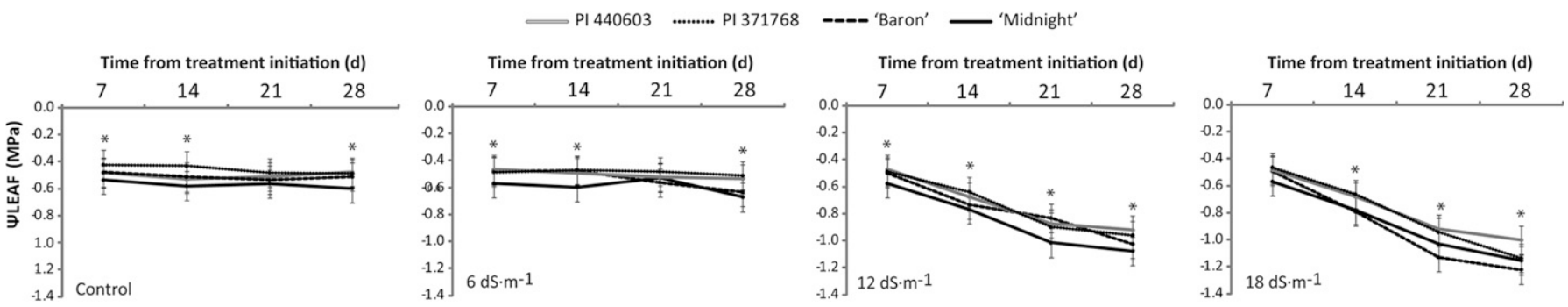

Fig. 3. Leaf water potential responses of four kentucky bluegrass entries under increasing salt treatments and for $28 \mathrm{~d}$ of treatment. Error bars represent least significant difference values at $P<0.05$, and asterisks are shown adjacent to comparisons that were significantly different.
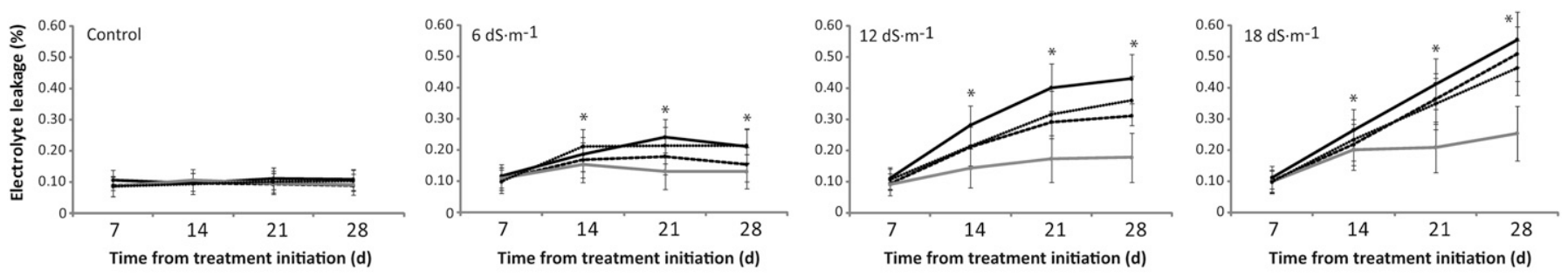

Fig. 4. Electrolyte leakage responses of four kentucky bluegrass entries under increasing salt treatments and for $28 \mathrm{~d}$ of treatment. Error bars represent least significant difference values at $P<0.05$, and asterisks are shown adjacent to comparisons that were significantly different.

entries. By $18 \mathrm{dS} \cdot \mathrm{m}^{-1}$ salt treatment, PI 440603 still showed the lowest EL values, followed by PI 371768 and 'Baron', and then 'Midnight' (Fig. 4). The EL measurements exhibited greater separation between entries than TQ, $g_{\mathrm{S}}$, or $\psi \mathrm{LEAF}$.

Correlations among the four repeated measures were significant, with EL negatively correlated with the other three (Table 1). Using TQ as a tolerance reference, only $\psi$ LEAF and EL were highly correlated with it at $r=0.72$ and $r=-0.71$ (both $P<0.01)$, respectively. $g_{\mathrm{S}}$ was correlated to a lesser degree with TQ, at $r=0.45(P<0.01)$. $g_{\mathrm{S}}$ was also correlated to a lesser degree with $\psi \mathrm{LEAF}$ and EL, at $r=0.48$ and $r=-0.31$ (both $P<$ 0.01 ), respectively.

As resilience to salt stress can come from an accumulation of inorganic ions, $\mathrm{Mg}, \mathrm{K}, \mathrm{Na}$, and $\mathrm{Ca}$ concentrations in control and $6 \mathrm{dS} \cdot \mathrm{m}^{-1}$ treated aboveground plant material were measured. Entries were significantly different for $\mathrm{Mg}$ and $\mathrm{K}$, but not $\mathrm{Na}$ or Ca. Treatment was significant for all four inorganic ions, whereas the interaction effects between entries and treatment were not significant. Mg levels dropped significantly on salt treatment, but PI 440603 exhibited higher Mg concentrations than the other three entries (Fig. 5). Although higher K concentrations have been shown to be important for salt
Table 1. Correlations between TQ, $g_{\mathrm{S}}, \psi \mathrm{LEAF}$, and EL among four kentucky bluegrass entries and salt treatments.

\begin{tabular}{lcccc}
\hline & TQ & $g_{\mathrm{S}}$ & $\psi$ LEAF & EL \\
\hline TQ & - & & & \\
$g_{\mathrm{S}}$ & $0.45^{* *}$ & - & & \\
$\psi \mathrm{LEAF}$ & $0.72^{* *}$ & $0.48^{* *}$ & - & \\
EL & $-0.71^{* *}$ & $-0.31^{* *}$ & $-0.78^{* *}$ & -
\end{tabular}

$\overline{\mathrm{TQ}}=$ turf quality; $\psi \mathrm{LEAF}=$ leaf water potential; $\mathrm{EL}=$ electrolyte leakage; $g_{\mathrm{S}}=$ stomatal conductance.

** Significant at $P<0.01$.

tolerance in many plants (Shabala and Cuin, 2008), K levels in this study dropped on salt treatment, and the four entries were not significantly different (Fig. 5). Na and Ca levels increased substantially on salt treatment, indicating unrestrained uptake of the $\mathrm{NaCl}$ and $\mathrm{CaCl}_{2}$ from the irrigation solution and its storage in the leaves. The variation of $\mathrm{Na}$ and $\mathrm{Ca}$ among replicates within entries was tremendous, such that differences between entries for these two elements were not significant (Fig. 5). With the high variation of $\mathrm{Na}$ concentrations among salt-treated entries, the differences between entries for the K:Na 

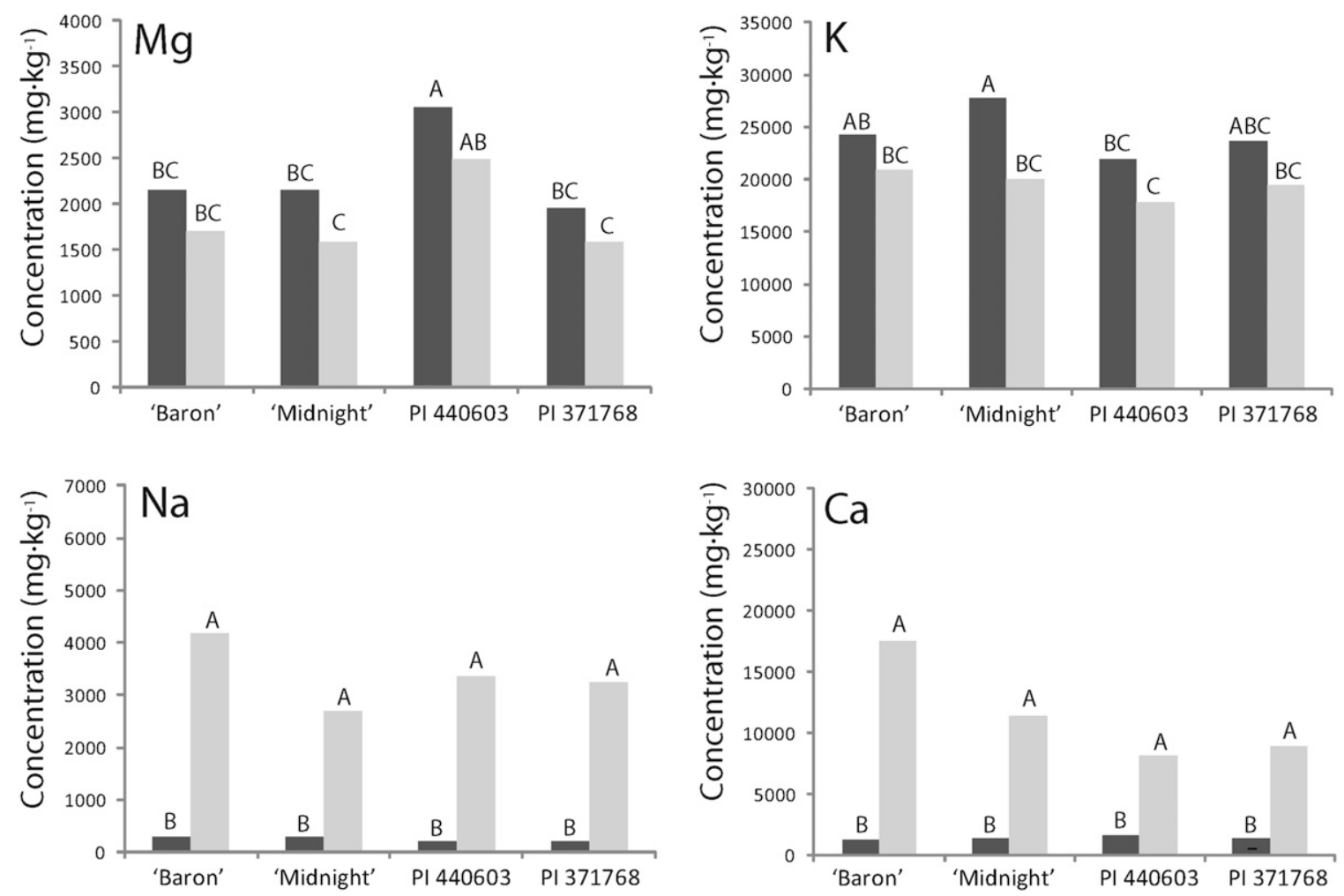

Fig. 5. Concentrations on inorganic ions in leaves and stems of four kentucky bluegrass entries upon control and $6 \mathrm{dS} \cdot \mathrm{m}^{-1}$ salt treatment. Alphabetical designations represent least significant differences at $P<0.05$.

ratio were also insignificant (data not shown). Patterns of correlations among inorganic ion concentrations were detected between $\mathrm{Na}, \mathrm{Ca}$, and $\mathrm{K}$ (Table 2). Ca and $\mathrm{Na}$ were highly and positively correlated with each other $(r=0.86, P<0.01)$ and negatively correlated with $\mathrm{K}(r=-0.46$ to $-0.48, P<0.01)$. $\mathrm{Mg}$ content was not significantly correlated with the other inorganic ions.

Several genes involved in ion transport across membranes and antioxidant activities, and detected as differentially expressed between a tolerant and susceptible kentucky bluegrass accession in Bushman et al. (2016), were tested for differential transcript abundances in the four entries. A plasma membrane $\mathrm{H}^{+}$-ATPase was induced in PI 440603 and PI 371768 on salt stress while significantly decreased in the cultivars Midnight and Baron (Fig. 6). Two splice variants of a V-type proton ATPase subunit d were significantly induced, but only variant 2 was induced to a greater degree in the tolerant PI 440603 and PI 371768. A TIP4-1 homolog was also induced in the more tolerant lines compared with susceptible entries, and induced on salt stress. Of the three antioxidant functioning genes, GAPDH showed a general response to salt imposition in all four entries, not ranking with the relative tolerances of the entries (Fig. 7). GST transcripts were induced by salt imposition in 'Baron' and 'Midnight' to a greater degree than PI 371768 , and were not induced in PI 440603 (Fig. 7). This expression pattern was consistent with GST functioning to ameliorate oxidative stress, which stress would be lower in the more tolerant PI 440603 and PI 371768 accessions. The thioredoxin h-type transcripts were induced on salt stress in all entries, and induced to greater levels in PI 440603 and PI 371768 .
Table 2. Correlations between $\mathrm{Mg}, \mathrm{K}, \mathrm{Na}$, and $\mathrm{Ca}$ concentrations in leaves and stems of four kentucky bluegrass entries after $28 \mathrm{~d}$ of treatment at $6 \mathrm{dS} \cdot \mathrm{m}^{-1}$ salt treatment.

\begin{tabular}{lcccc}
\hline & $\mathrm{Mg}$ & $\mathrm{K}$ & $\mathrm{Na}$ & $\mathrm{Ca}$ \\
\hline $\mathrm{Mg}$ & - & & & \\
$\mathrm{K}$ & $-0.08^{\mathrm{Ns}}$ & - & & \\
$\mathrm{Na}$ & $-0.14^{\mathrm{Ns}}$ & $-0.46^{* *}$ & - & \\
$\mathrm{Ca}$ & $-0.18^{\mathrm{Ns}}$ & $-0.48^{* *}$ & $0.86^{* *}$ & -
\end{tabular}

${ }^{\mathrm{N}}$ Nonsignificant and $* *$ significant at $P<0.01$.

\section{Discussion}

With salt stress imposition on turfgrass a persistent and growing problem, exacerbated by an increased use of effluent water for landscapes and golf courses (Lockett et al., 2008), multiple studies have included kentucky bluegrass and examined TQ under salt stress (Alshammary et al., 2004; Horst and Taylor, 1983; Koch and Bonos, 2010; Koch et al., 2011; Liu et al., 2011; Poss et al., 2010; Qian et al., 2001; Robins et al., 2009; Rose-Fricker and Wipff, 2001; Suplick-Ploense et al., 2002; Torello and Rice, 1986). Those studies employed various measures to explore mechanisms by which their respective entries responded to salt stress, but always included an assessment of TQ as a reference. For those that included correlations, the measures were highly correlated with each other and with TQ (Koch et al., 2011). In this study, we assessed TQ with the other repeated measures of $g_{\mathrm{S}}, \psi \mathrm{LEAF}$, and EL, and each was significantly correlated with TQ (Table 1). However, $g_{\mathrm{S}}$ measurement variation was more prone to evanescent environmental conditions, was more difficult to 

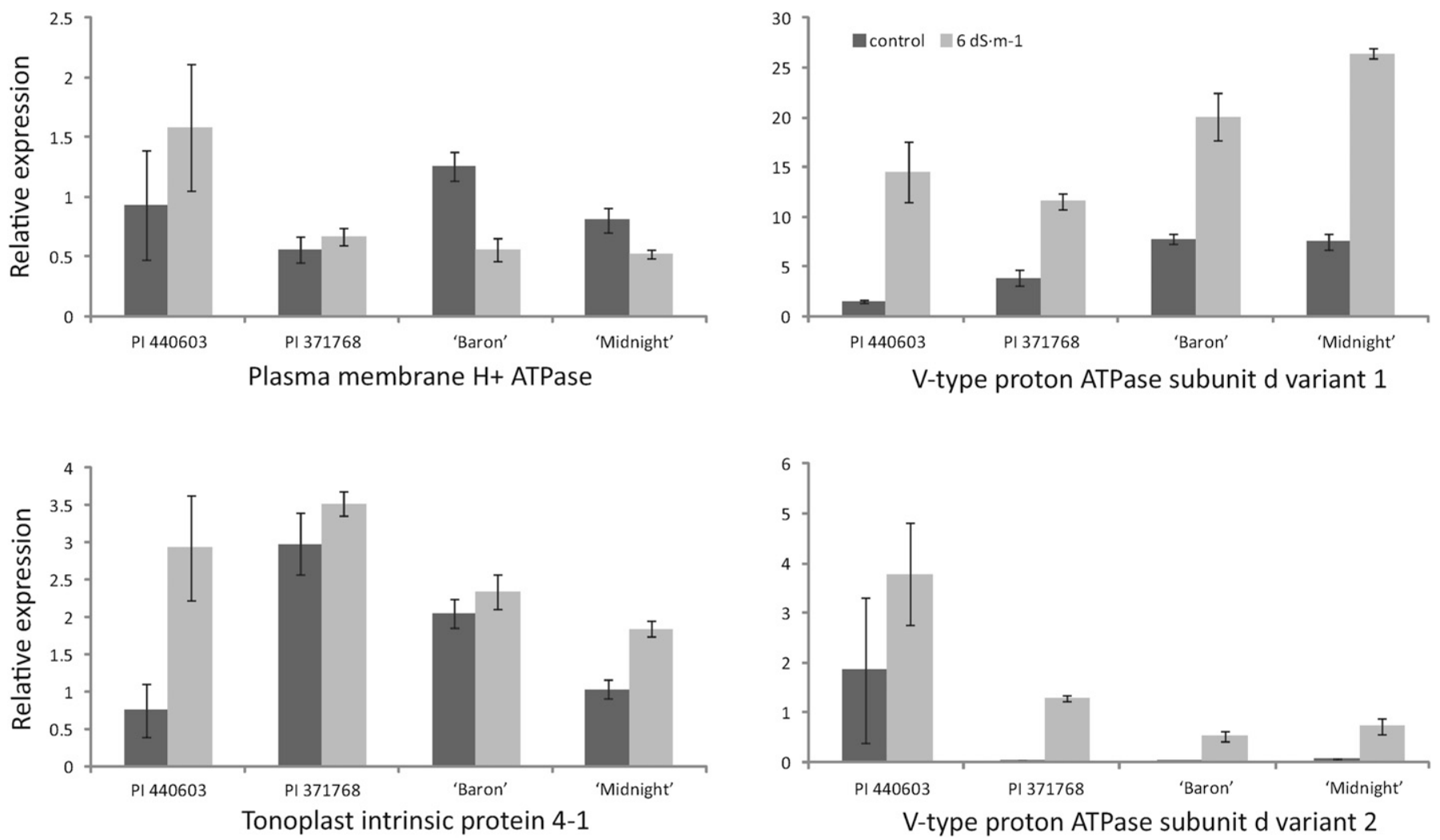

Fig. 6. Relative gene expression (relative to $\beta$-tubulin) of four gene transcripts related to membrane ion transport in four kentucky bluegrass entries, and under control and $6 \mathrm{dS} \cdot \mathrm{m}^{-1}$ salt treatment. Error bars represent standard errors of the means.

assay due to narrow turf leaves, and had a lower correlation to the other three repeated measurements. Of the four measures, EL was the most consistent and had the greatest ability to discriminate between tolerant and susceptible entries; even at lower salt treatments. With a goal to supplant environmentsensitive metrics and hone in on consistent and germane phenotype measurements for tolerance to salt stress, these data highlight that both EL and $\psi$ LEAF were accurate and highly correlated with TQ, whereas EL had a greater sensitivity to discriminate salt effects.

Many of the previous studies found differences in tolerance rankings of the same cultivars. Two such cultivars often included in salt tolerance assays were Baron and Midnight. The former was found to be relatively salt tolerant in several studies (Horst and Taylor, 1983; Koch and Bonos, 2010; Poss et al., 2010); but relatively intolerant to salt in others (Koch et al., 2011; Torello and Rice, 1986). 'Midnight' was found to be intolerant of salt stress in some studies (Koch and Bonos, 2010; Poss et al., 2010), but showed greater than average tolerance (Koch et al., 2011) or was used as a tolerant control (Puyang et al., 2015) in other studies. The rank changes of relative tolerance across the studies are intriguing, because most of the studies were conducted under strict greenhouse or hydroponic conditions and the measures are often highly correlated. One possible source of variation would be the seasonal climates affecting greenhouse conditions, whereupon an entry may be tolerant to salt under cool humid winter experiments, but less so under hotter and higher ultraviolet light in summer experiments. Alternatively, as old cultivars of kentucky bluegrass whose genetic identity may have drifted over time, variation in seed sources may account for some of the variation reported in entry responses. Regardless, using the cultivars Baron and Midnight as checks, we attempted to confirm salt tolerance of germplasm that were significantly more salt tolerant than both cultivars. Two accessions previously exhibited $\mathrm{LD}_{50}$ values at significantly higher salt concentrations than 'Midnight' in Robins et al. (2009); PI 371768 from a cool coastal area in Alaska, and PI 440603 from a hot dry climate in central Asia. Of these two putatively tolerant accessions, PI 440603 was more tolerant of salt stress than PI 371768, and both were more tolerant than 'Baron' or 'Midnight'. Furthermore, our results further indicate that 'Baron' is relatively more tolerant of salt stress than 'Midnight'. For intended turf uses in saline environments, PI 440603 in particular can provide a novel genetic source of salt tolerance.

Grasses can grow under saline conditions by excluding $\mathrm{Na}$ from growing shoots, or by tempering the $\mathrm{Na}$ concentrations with a higher preference for K (Marcum, 2008). Ca can also ameliorate the effects of excessive $\mathrm{Na}$ by accumulating in cells and inducing stress response signaling cascades (Bressan et al., 2008). In this study, we measured the ion concentrations of $\mathrm{Na}$, $\mathrm{Ca}, \mathrm{K}$, and $\mathrm{Mg}$ from two of the three experimental runs, and for the control and $6 \mathrm{dS} \cdot \mathrm{m}^{-1}$ treatment. $\mathrm{Na}$ and $\mathrm{Ca}$ were induced on salt treatment, whereas $\mathrm{K}$ and $\mathrm{Mg}$ levels decreased. This $\mathrm{Na}$ increase is consistent with Alshammary (2013) and Xu and Fujiyama (2013), who reported that $\mathrm{Na}$ concentrations increased linearly in response to the amounts added and suggesting that kentucky bluegrass in general does not exclude $\mathrm{Na}$ from reaching and accumulating in the shoots. In our study, even the 

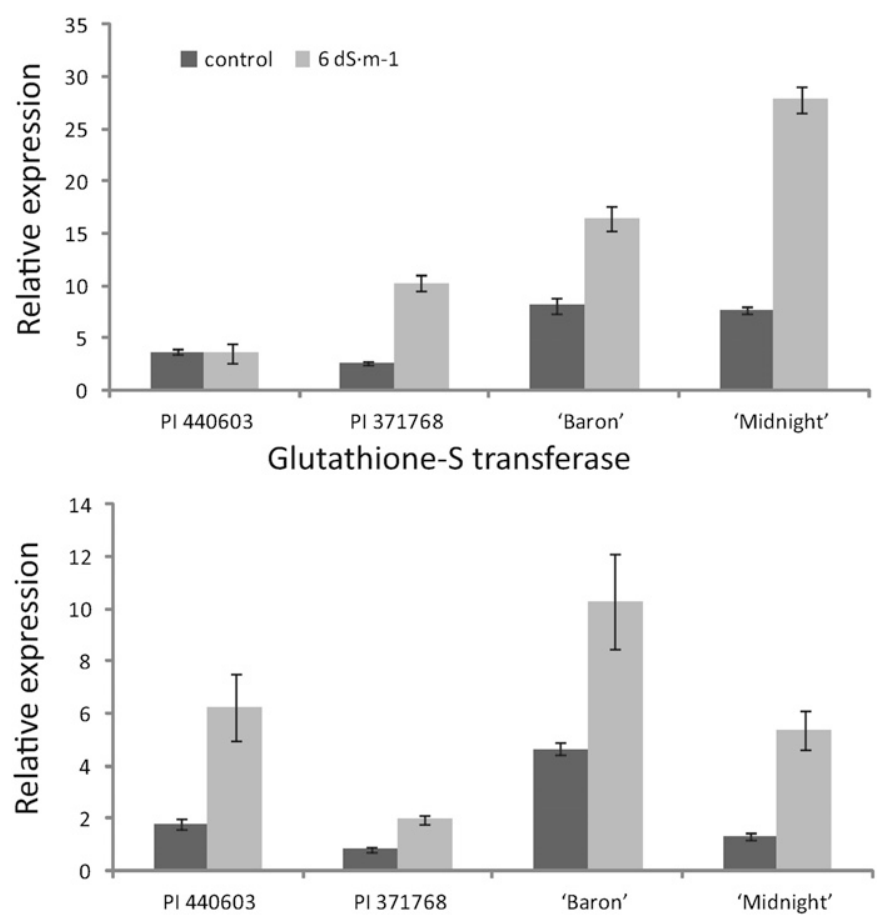

Glycerol 3-P dehydrogenase

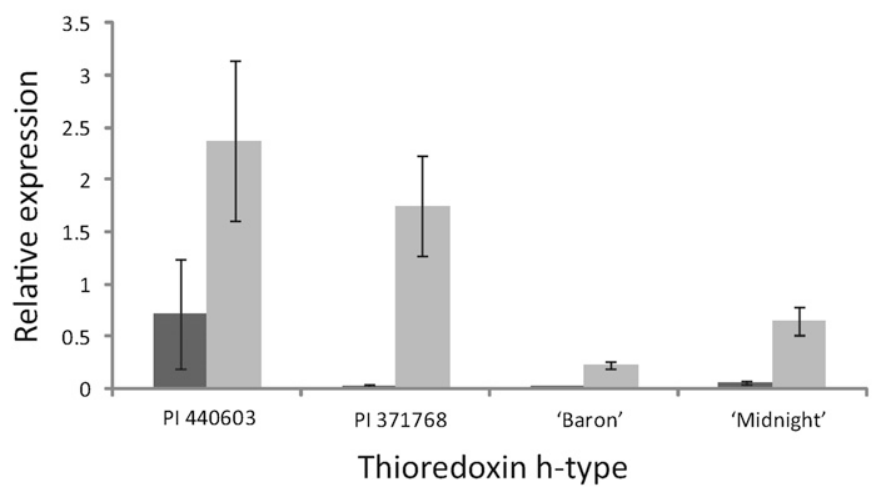

Fig. 7. Relative gene expression (relative to $\beta$-tubulin) of three gene transcripts related to antioxidant activity in four kentucky bluegrass entries, and under control and $6 \mathrm{dS} \cdot \mathrm{m}^{-1}$ salt treatment. Error bars represent standard errors of the means.

tolerant PI 440603 accumulated the $\mathrm{Na}$ as much as 'Midnight'. The $\mathrm{K}$ concentrations and the $\mathrm{K}: \mathrm{Na}$ ratios were also not significant between tolerant and susceptible entries, unlike the results of Qian et al. (2001), Alshammary (2013), and Xu and Fujiyama (2013). The difference may lie in the treatment concentrations, where those previous reports found significant differences between inorganic ion concentrations at higher salt treatment levels, while our study examined only $6 \mathrm{dS} \cdot \mathrm{m}^{-1}$ compared with control. At the $6 \mathrm{dS} \cdot \mathrm{m}^{-1} \mathrm{EC}$ salt concentration, which is a similar EC level to most effluent irrigation water (Marcum, 2006) or soil in semiarid locations (Lesch et al., 2005); all four entries shared an ability to accumulate similar concentrations of inorganic ions. One exception resides in $\mathrm{Mg}$, which was significantly higher in PI 440603. Although little is known about the role $\mathrm{Mg}$ might play in salt response and tolerance (Alshammary, 2013), the increased concentration in the most tolerant line warrants further investigation.
Although concentrations of $\mathrm{Na}$ and $\mathrm{K}$ did not vary significantly among the four entries, those concentrations were measured on the whole leaf and would not discriminate between concentrations in the vacuole vs. the cytosol. In addition, as EL and $\psi \mathrm{LEAF}$ were strong indicators of tolerance in PI 440603 and PI 371768, those entries were likely better able to maintain ionic homeostasis and water potential in the cells of salt-stressed plants. After an initial shock from salt stress, plants adjust to increased saline conditions by maintaining cellular ionic homeostasis in the cytosol. This maintenance requires energy and is done by exporting $\mathrm{Na}$ to the apoplast or vacuole, and importing $\mathrm{K}$ to the cytosol to maintain osmotic potential (Alshammary, 2013; Hasegawa et al., 2000; Marcum, 2008). A previous transcriptome expression experiment (Bushman et al., 2016), using an accession related to PI 371768 (Robins et al., 2009), found several genes related to ion transport across the plasma membrane and the tonoplast membrane that were differentially expressed between control and salt treatments. A plasma membrane $\mathrm{H}^{+}$-ATPase and a tonoplast V-type ATPase subunit were also induced in the more tolerant entries in this study, even at the lower $6 \mathrm{dS} \cdot \mathrm{m}^{-1}$ salt treatment, such that the previous results were confirmed for these genes and a mechanism provided for their improved tolerance to salt. The induction of these two genes suggests that one of kentucky bluegrass' mechanisms for maintaining ionic homeostasis may be to transport $\mathrm{Na}$ out of the cytosol to the apoplast via the plasma membrane $\mathrm{H}^{+}$-ATPase-mediated gradient, and to the vacuole via the V-type ATPase-mediated gradient. In addition, the higher TIP4-1 transcript levels suggest increased water movement across the tonoplast to maintain the necessary water potential (Hasegawa et al., 2000).

When $\mathrm{Na}$ ions accumulate in the cytosol despite cellular attempts to remove or sequester them, genes with antioxidant functions can be employed to minimize cell damage caused by those ions (Hasegawa et al., 2000). Previously, in Bushman et al. (2016), several reactive oxygen species (ROS) scavenging and antioxidant genes were induced in the tolerant kentucky bluegrass accession related to PI 371768. Of three antioxidant genes tested herein, GST and GAPDH showed a significant and general salt stress response in all entries rather than increased induction in tolerant entries. However, the thioredoxin h-type was induced in PI 440603 to the greatest extent, followed by PI 371768 and 'Baron' (Fig. 4). As predominantly cytoplasmic proteins, thioredoxins have been reported to respond to salt stress by scavenging ROS in the apoplast (Zhang et al., 2011). In this study, where the thioredoxin h-type was expressed at an equal or higher level in control plants of PI 440603 than even salt-treated plants of 'Midnight', it likely plays a role in PI 440603s ability to reduce the harmful effects of oxidative stress.

In this study, we confirmed a previous finding by Robins et al. (2009) wherein PI 440603 was highly tolerant of salt stress for kentucky bluegrass, and PI 371768 was somewhat less tolerant than PI 440603. We also provided insight into how these plants respond to and tolerate salt stress. The more tolerant lines showed higher TQ, higher $\psi \mathrm{LEAF}$, and lower EL under salt stress. The latter measure, in particular, was consistent and sensitive in its ability to discern tolerant lines from the cultivars Baron and Midnight, and suggested the role of membrane ion transport and cellular antioxidant mechanisms for the cause of salt-stress tolerance. As kentucky bluegrass is a high polyploid with a challenging breeding system, these 
results can be used to provide salt-tolerant germplasm for kentucky bluegrass cultivar improvement, allow research to more efficiently screen for further salt-tolerant lines, and focus on genes and genetic mechanisms wherewith to improve selection for salt tolerance.

\section{Literature Cited}

Alshammary, S.F. 2013. Effect of salinity on ion relations of four turfgrasses. J. Food Agr. Environ. 11:1321-1326.

Alshammary, S.F., Y.L. Qian, and S.J. Wallner. 2004. Growth response of four turfgrass species to salinity. Agr. Water Mgt. 66:97-111.

Blum, A. and A. Ebercon. 1981. Cell membrane stability as a measure of drought and heat tolerance in wheat. Crop Sci. 21:43-47.

Bressan, R.A., H.J. Bohnert, and P.M. Hasegawa. 2008. Genetic engineering for salinity stress tolerance, p. 347-384. In: H.J. Bohnert, H. Nguyen, and N.G. Lewis (eds.). Advances in plant biochemistry and molecular biology. Pergamon Press, Oxford, UK.

Bushman, B.S., K.L. Amundsen, S.E. Warnke, J.G. Robins, and P.G. Johnson. 2016. Transcriptome profiling of kentucky bluegrass (Poa pratensis L.) accessions in response to salt stress. BMC Genomics 17:1-12.

Carrow, R.N. and R.R. Duncan. 1998. Salt-affected turfgrass sites: Assessment and management. Wiley, Hoboken, NJ.

Hasegawa, P.M., R.A. Bressan, J.K. Zhu, and H.J. Bohnert. 2000. Plant cellular and molecular responses to high salinity. Annu. Rev. Plant Physiol. Plant Mol. Biol. 51:463-499.

Horst, G.L. and R.M. Taylor. 1983. Germination and initial growth of kentucky bluegrass in soluble salts. Agron. J. 75:679-681.

Hurley, R.H. and H. Ghijsen. 1980. Registration of Baron kentucky bluegrass. Crop Sci. 20:549-550.

Hutchinson, F.E. 1970. Environmental pollution from highway deicing compounds. Soil Water Conservation 25:144-146.

Koch, M.J. and S.A. Bonos. 2010. An overhead irrigation screening technique for salinity tolerance in cool-season turfgrasses. Crop Sci. 50:2613-2619.

Koch, M.J., B.R. Huang, and S.A. Bonos. 2011. Salinity tolerance of kentucky bluegrass cultivars and selections using an overhead irrigated screening technique. Crop Sci. 51:2846-2857.

Leksungnoen, N., R.K. Kjelgren, R.C. Beeson, P.G. Johnson, G.E. Cardon, and A. Hawks. 2014. Salt tolerance of three tree species differing in native habitats and leaf traits. HortScience 49:1194-1200.

Lesch, S.M., D.L. Corwin, and D.A. Robinson. 2005. Apparent soil electrical conductivity mapping as an agricultural management tool in arid zone soils. Comput. Electron. Agr. 46:351-378.

Lesch, S.M. and D.L. Suarez. 2009. Technical note: A short note on calculating the adjusted SAR index. Trans. Amer. Soc. Agr. Biol. Eng. 52:493-496.

Liu, L.M., H.M. Du, K. Wang, B.R. Huang, and Z.L. Wang. 2011. Differential photosynthetic responses to salinity stress between two perennial grass species contrasting in salinity tolerance. HortScience $46: 311-316$.
Lockett, A.M., D.A. Devittz, and R.L. Morris. 2008. Impact of reuse water on golf course soil and turfgrass parameters monitored over a 4.5-year period. HortScience 43:2210-2218.

Marcum, K.B. 2006. Use of saline and non-potable water in the turfgrass industry: Constraints and developments. Agr. Water Mgt. 80:132-146.

Marcum, K.B. 2008. Physiological adaptations of turfgrasses to salinity stress, p. 407-417. In: M. Pessarakli (ed.). Turfgrass management and physiology. CRC Press, Boca Raton, FL.

Meyer, W.A., B.L. Rose, J.M. Johnson-Cicalese, and C.R. Funk. 1984. Registration of Midnight kentucky bluegrass. Crop Sci. 24:822-823. Miller, R.O. 1998. High-temperature oxidation: Dry ashing, p. 53-56. In: Y.P. Kalra (ed.). Handbook and reference methods for plant analysis. CRC Press, Boca Raton, FL.

Munns, R. 2005. Genes and salt tolerance: Bringing them together. New Phytol. 167:645-663.

Pitman, M.G. and A. Lauchli. 2002. Global impact of salinity and agricultural ecosystems, p. 3-20. In: A. Lauchli and U. Luttge (eds.). Salinity: Environment-Plants-Molecules. Springer, Dordrecht, The Netherlands.

Poss, J.A., W.B. Russell, S.A. Bonos, and C.M. Grieve. 2010. Salt tolerance and canopy reflectance of kentucky bluegrass cultivars. HortScience 45:952-960.

Puyang, X., M. An, L. Han, and X. Zhang. 2015. Protective effect of spermidine on salt stress induced oxidative damage in two kentucky bluegrass (Poa pratensis L.) cultivars. Ecotoxicol. Environ. Saf. 117:96-106.

Qian, Y.L., S.J. Wilhelm, and K.B. Marcum. 2001. Comparative responses of two kentucky bluegrass cultivars to salinity stress. Crop Sci. 41:1895-1900.

Robins, J.G., B.S. Bushman, B.L. Waldron, and P.G. Johnson. 2009. Variation within Poa germplasm for salinity tolerance. HortScience 44:1517-1521.

Rose-Fricker, C. and J.K. Wipff. 2001. Breeding for salt tolerance in cool-season turfgrasses. Intl. Turfgrass Soc. Res. J. 9:206-212.

Shabala, S. and T.A. Cuin. 2008. Potassium transport and plant salt tolerance. Physiol. Plant. 133:651-669.

Suplick-Ploense, M.R., Y.L. Qian, and J.C. Read. 2002. Relative $\mathrm{NaCl}$ tolerance of kentucky bluegrass, texas bluegrass, and their hybrids. Crop Sci. 42:2025-2030.

Szabolcs, I. 1989. Salt affected soils. CRC Press, Boca Raton, FL.

Torello, W.A. and L.A. Rice. 1986. Effects of $\mathrm{NaCl}$ stress on proline and cation accumulation in salt sensitive and tolerant turfgrasses. Plant Soil 93:241-247.

$\mathrm{Xu}, \mathrm{R}$. and H. Fujiyama. 2013. Comparison of ionic concentration, organic solute accumulation and osmotic adaptation in kentucky bluegrass and tall fescue under $\mathrm{NaCl}$ stress. Soil Sci. Plant Nutr. 59:168-179.

Zhang, C-J., B-C. Zhao, W-N. Ge, Y-F. Zhang, Y. Song, D-Y. Sun, and Y. Guo. 2011. An apoplastic h-type thioredoxin is involved in the stress response through regulation of the apoplastic reactive oxygen species in rice. Plant Physiol. 157:1884-1899. 
Supplemental Table 1. Primer sequences used for quantitative real-time reverse-transcription PCR of transport and antioxidant genes in kentucky bluegrass.

\begin{tabular}{lll}
\hline Gene & \multicolumn{1}{c}{ Forward primer } & Reverse primer \\
\hline$\beta$-tubulin & GTGGAGTGGATCCCCAACAA & AAAGCCTTCCTCCTGAACATGG \\
plasma membrane H+ ATPase & TATCTGGGGCAGTTCTGCTT & CAGGCAACATTTACAGTGCTC \\
V-type ATPase subunit d var. 1 & AGAACACCGTCGCCTACATC & GCGACCTTCTCCAAAGCATA \\
V-type ATPase subunit d var. 2 & GGCATGTGGGGTATTTGATT & GGCGAAAGTGGCCAGTAATA \\
tonoplast intrinsic protein 4-1 & ACAGAGGTGTGCATGATGGT & TGATCTTCTCCTTCATCCCCTA \\
glutathione S-transferase & AATACCACGAGCGGAAACAC & GAACTTTCACCCATGCCAGT \\
glycerol 3-phosphate dehydrogenase & GGTTTCATCACCGTCGACCT & GAGCGAGCGTAGGTATAACTGAT \\
thioredoxin h-type & CAATGTGCTACTAAATTCAGATTTCC & TAGGATTGCCGAACATAACG \\
\hline
\end{tabular}

